\title{
NOVAS MANEIRAS DE RESSIGNIFICAR, DE PARTICIPAR E DE COLABORAR NA ERA DA MOBILIDADE INFORMACIONAL
}

\author{
NEW WAYS OF RESIGNIFING, PARTICIPATING AND COLABORATING IN THE \\ INFORMATION MOBILITY ERA
}

\author{
Vagner Aparecido de Moura \\ Moura Neuro-Humanities Lab, Brasil \\ vagner.moura420@gmail.com
}

RESUMO: As cidades desplugadas, na era da supermodernidade, impelem-nos a discutir, no presente artigo, o termo mobilidade informacional, com a finalidade de desnaturatizá-lo e trazer, à baila, as adversidades subjacentes a essa nova forma de subjetivação, de individuação e de mobilidade. Para lograr êxito nesse processo hermenêutico e investigativo, será utilizado como procedimento metodológico a revisão de literatura, embasada nos seguintes autores: Lemos (2007a, 2007b, 2008, 2009), Rivière (2006) e Tuan (2003). A intenção é de não só discutir as implicações entre mobilidade versus comunicação de massa, o processo de configuração e a reconfiguração do território informacional, mas também empoderar o coenunciador a tornar-se um "bricoleur" da transmodernidade, com 0 intuito de discutir o conceito de identidade na contemporaneidade e, assim, ressignificar o seu olhar no momento em que participa, colabora no processo de construção de novas maneiras de estabelecer vínculos e laços de pertencimento.

PALAVRAS-CHAVE: mobilidade informacional; cidades desplugadas; individuação; subjetivação.

\begin{abstract}
The unplugged cities, in the age of Supermodernity, lead us to discuss the term informational mobility in this article, aiming at denaturalizing it and bringing up underlying adversities to this new manner of subjectivation, individuation and mobility. In order to succeed in this hermeneutic and investigative process, the literature review will be used as methodological procedure, based on the following authors: Lemos (2007a, 2007b, 2008, 2009), Rivière (2006) and Tuan (2003). The intention is not only to discuss the implications between mobility and mass communication, the configuration process and informational territory's reconfiguration, but also to empower the co-enunciator to become a "bricoleur" of the transmodernity, make possible to discuss the concept of identity in the contemporary society and, thus, to resignify his look at the time he is part of, collaborating in the building process of new ways of establishing links and the belonging feeling.
\end{abstract}

KEYWORDS: informational mobility; unplugged cities; individuation; subjectivation.

\section{Considerações iniciais}

A terceira revolução tecnológica potencializa o fenômeno da mobilidade social, entendida como uma relação que engloba tanto o espaço urbano como as formas 
comunicacionais. Sendo assim, cabe nesse momento de prelúdio do tema, discutir o valor semântico do lexema mobilidade, com a finalidade de que, o meu coenunciador, compreenda as fases e as implicações do termo mobilidade na cidade. Deve-se salientar que os sociólogos do fim do século XIX, Simmel, Tarde e Park, discutem três tipos de mobilidade. A primeira refere-se ao homem em movimento; neste caso, a cidade transforma o sujeito, já que vivencia as experiências pelo olhar, daí a gênese da figura do estrangeiro de Simmel que observa tudo e fora. A segunda mobilidade urbana está relacionada à mobilidade social e do lugar de habitação; nesse cenário, o habitante (o ator social) explora um processo de deslocamento constante e com isso pode cambiar de status e de papel social por meio da educação. A terceira, Simmel cognomina mobilidade sem deslocamento; em outras palavras, a mobilidade que constitui/cria uma moda: a mobilidade social por intermédio da moda permite-nos aderir ao comum e concomitantemente nos diferencia. Além disso, existe o quarto valor semântico do termo mobilidade que corresponde à mobilidade informacional (objeto de estudo deste artigo), que pode ser entendida como uma potencialidade cognitiva de desligamento por meio de bens simbólicos, por mensagens e por informações.

Tal potencialidade cognitiva consubstancia-se pelas mídias as quais reconfiguram os espaços urbanos, os subúrbios, os centros e dinamizam os meios de transporte público e, deste modo, tornam mais densos e complexo o organismo-rede que são as cidades. Lemos (2007a, p. 122) pontua que "mobilidade e cidade são indissociáveis". Essa relação, na supermodernidade, impele-nos (tanto o enunciador quanto o coenunciador ávidos por informação e por entretenimentos nas megacidades) a perceber que, atualmente, as sociedades configuram e reconfiguram-se como sociedades em redes física, simbólica, cultural, política e imaginária, constituindo, assim, um espaço urbano, alicerçado em várias maneiras de se estabelecer vínculos sociais.

Tais vínculos ocorrem por meio da particularidade das sociedades contemporâneas: hegemonia de um conjunto de redes. Lemos (2007a, p. 122-123) alertanos ao fato de que "o processo de complexificação do organismo-rede, contínua com as metrópoles cibernéticas contemporâneas, as cibercidades" e ressalta que "estas podem ser definidas como cidades onde a infraestrutura de comunicação e informação são uma realidade e as práticas daí advinda formam uma nova urbanidade".

É relevante pontuar que o ator social deve ser anuente e reconhecer que novas dinâmicas e práticas sociais demandam reconfigurações e infraestruturas, aliadas à tecnologia de comunicação e a redes telemáticas, uma vez que se observa, no cotidiano e na prática laboral dos indivíduos, que a tecnologia sem fio (como dispositivos e redes: os celulares 3G, GPS, Palms, redes Wi-Fi, Wi-Max, Bluetooth), está transformando as maneiras de ressignificar, de participar e de colaborar nas relações intersubjetivas, constituindo, deste modo, novas maneiras de mobilidade, de subjetivação e de individuação. Essas metrópoles estão se tornando cidades "desplugadas"; em outras palavras, "um ambiente de generalização de conexão, envolvendo o usuário em plena mobilidade, interligando máquinas, pessoas e objetos urbanos" (LEMOS, 2007a, p. 123). Outros teóricos referem-se a essa nova configuração entre o sujeito e o espaço como uma forma de compressão espaço-temporal (HARVEY, 1992), de desterritorialização (DELEUZE; GUATARRI, 1980) e de espaços líquidos (BAUMAN, 2001).

Esse cenário multifacetado impulsiona-nos a discutir, no corpo deste artigo, por meio de uma revisão de literatura, embasada nos seguintes autores: Lemos (2007a, 
2007b, 2008, 2009), Rivière (2006) e Tuan (2003), o termo mobilidade informacional, com intuito de desnaturalizá-lo e trazer, à baila, as adversidades subjacentes a essa nova forma de subjetivação e de mobilidade: os embates em termos de fronteiras, do processo de individuação do sujeito, da formação de uma transidentidade e das vozes uníssonas e dissonantes que compõem o cenário cultural e político desse organismo-rede. Para lograr êxito, neste percurso epistemológico, serão abordadas as implicações entre mobilidade versus comunicação de massa, o processo de configuração e a reconfiguração do território informacional e o conceito de identidade na sobremodernidade.

\title{
2 Mobilidade versus comunicação de massa
}

\begin{abstract}
O transporte à distância do "pensamento e da força", que vai criar as redes das primeiras cidades modernas, vai ganhar novas dimensões nos séculos XIX com a revolução industrial e as mídias de função massiva, e no final do século XX e início desse século XXI, com a era pós-industrial e a emergência de processos comunicativos com funções pós massivas (LEMOS, 2007a, p. 124).
\end{abstract}

Evidencia-se que, no século XIX, a função massiva abarcava, de maneira centralizada, um fluxo de informação com o controle do processo editorial e do polo de emissão pelos conglomerados comunicacionais. Nesse cenário, os conglomerados têm como objetivo lançar os hits, ou seja, o sucesso do grande público, por meio de trocas simbólicas que possibilitem um caráter homogêneo da cultura, permeado de vozes uníssonas. Tal estratagema tem como finalidade não só as verbas publicitárias e o lucro, mas também influenciar, em virtude de seu papel social e político na sociedade, na formação do público e na opinião pública na modernidade.

Contrapondo, as mídias de função pós-massiva, no final do XX e início do século XXI, constituem uma ruptura de paradigma com o modelo unidirecional de comunicação, uma vez que funcionam por intermédio de redes telemáticas em que qualquer ator social pode produzir, compartilhar informações. Devem ressaltar-se que as funções pósmassivas não estão centralizadas sobre um território específico, mas sim de maneira virtual sobre o orbe. Além disso, o produto é customizado possibilitando ao enunciador da informação não ser movido ou impulsionado por hits, mas por nichos que constituem "uma longa cauda", isto é, a possibilidade de ofertar, por meio da estrutura rizomática da comunicação, vários produtos de abrangência local e global. Esse produto de caráter imaterial e intangível materializa-se por intermédio de blogs, gravadoras e músicos, softwares livres, podcasting e wikis que mostram o potencial das mídias pós-massivas: plasmar múltiplas vozes dissonantes que compõem não uma identidade una, divisível ou "nacional", mas uma transidentidade. Em outras palavras, o diálogo continuum entre os sinais diacrítico de um Estado, de uma nação e dos laços de pertencimentos, coconstituídos pela memória dita não oficial e pelo caráter polifônico e multiforme das vozes dissonantes com a rubrica do não lugar.

É fulcral chamar atenção de meu coenunciador para o fato de que as funções massiva e pós-massiva devem ser pensadas em termos de função e não de dispositivos, visto que ambas estão presentes nas mídias tanto analógica, quanto digital. Lemos (2007a, p. 126) alerta-nos de que: 
Essa nova configuração comunicacional, mais rica, já que oferece cada vez mais funções massivas e pós-massivas, vai causar uma crise e alguns impactos importantes para configuração das novas relações sociais e comunicacionais (crise do copyright, jornalismo cidadão, software livre, trocas de arquivos em redes P2Petc).

Observa-se que a mescla entre a função massiva e pós-massiva possibilita o recrudescimento da potencialidade das novas práticas sociais na cibercultura: contato em tempo real e o acesso a uma gama de informações, novas maneiras de estabelecer relações de pertencimento um determinado grupo/comunidade e a autoexposição (You Tube, Facebook, Instagram). Contudo, nota-se que o internauta-espectador-consumidor é levado, de maneira inconsciente, a aderir, no compartilhamento dos vídeos, a um código simbólico do "like" e do "dislike" que traz, à tona", o processo de homogeneização da polifonia de vozes que engendra um fenômeno social de neutralidade, de ausência de criticidade, do simulacro da identidade una, visto que alteridade dilui-se no momento em que o internauta, atrelado à busca do consentimento do grande Outro, produz, publica, em tempo real, o seu conteúdo sob diversos formatos e modulações, customizadas para atender aos desejos e às necessidades do internauta.

É essencial pontuar que esse novo cenário engloba novas maneiras de apropriação do espaço urbano, nas palavras de Lemos (2007a, p. 128), "escrever e ler o espaço de forma eletrônica locativas (mapping, geolocalização, anotações urbanas, wireless, games), trazendo novas dimensões do uso e da criação de sentido nos espaços urbanos". Com o objetivo de aprofundar a questão que envolve o espaço urbano, pretende-se discutir, no próximo subitem, o conceito de territorialidade informacional e a presença dos dispositivos híbridos móveis de conexão multirredes (DHMCM).

\section{Configuração e a reconfiguração do território informacional}

Nesta nova dinâmica que se configura e se reconfigura entre o espaço físico e a tecnologia da informação, locomover-se pelas ruas dos grandes centros e pelos meios de transporte ou permanecer em casa com o acesso aos dispositivos móveis e redes sem fios possibilita-nos perceber as facilidades das áreas de fluxo informacional digital como uma zona ou região de intersecção entre o ciberespaço e o espaço urbano. Essa zona de intersecção constitui, por meio da rede de Wi-Fi, o território informacional que, segundo Lemos (2007a, p. 128), "não é o ciberespaço, mas o espaço movente, híbrido" que se configura pela constructo dialógico e polifônico tanto das redes quanto do espaço físico que permeia, na atualidade, o processo de socialização.

Ressalta-se que o território informacional cria um lugar dependente dos espaços físico e eletrônico, o qual o internauta-espectador-consumidor vincula-se, por exemplo, no parque, no aeroporto, no shopping center, nos meios de transportes público e privado no momento em que acessa a internet para se manter conectado com o universo do ciberespaço por meio da rede Wi-Fi. Tal fato demonstra-nos que não só o lugar consubstancia-se por intermédio das práticas sociais que estabelecem laços de pertencimento (simbólico, afetivo, econômico), mas também é, conforme Tuan (2003), a fixação enquanto que o espaço é abertura, visto que necessita de tempo e de experiência 
para se formar. É necessário frisar que a internet de baixo-custo possibilita que tais espaços constituam "um ambiente generalizado de acesso onde qualquer pessoa pode, dentro de seu território informacional constituído por intermédio de suas senhas de acesso, envio e recebimento de informações multimodais em mobilidade" (LEMOS, 2007a, p. 130). Nesse cenário, emerge uma nova maneira de mobilidade: a mobilidade por fluxos de informação, por território informacional que modifica a mobilidade pelos espaços físicos dos grandes centros populacionais, com a possibilidade de acesso, de produção e de circulação de informação em tempo real.

Evidencia-se que, na supermodernidade, o telefone celular pode ser pensado como um dispositivo híbrido móvel de conexão multirredes (DHMCM), visto que amplia a compreensão do dispositivo e rompe com a analogia com o telefone. Observa-se, no dia a dia, que o telefone celular é um dispositivo híbrido, porque aglutina várias funções: telefone, computador, máquina fotográfica, câmera de vídeo, processador de textos, GPS entre outras. Ademais, é um artefato móvel, isto é, portátil e conectado por redes de conexão e de multirredes, uma vez que pode agregar diversas redes tais como: Bluetooth e infravermelho para conexões de curta distância dentre outros dispositivos: celular para as várias possibilidades de troca de informações, internet (Wi-Fi ou Wi-Max) e redes de satélite para o uso do GPS.

O dispositivo híbrido móvel de conexão multirredes (DHMCM) potencializa, via conexão em rede, o fenômeno comunicativo (voz, texto, foto, vídeo) e a mobilidade por territórios informacionais. Tal dispositivo reconfigura as práticas sociais (entretenimento, laboral) de mobilidade informacional pelos espaços físicos das cidades. Nas palavras de Lemos (2007b, p. 24), "trata-se da ampliação da conexão, dos vínculos comunitários, do controle sobre a gestão do seu tempo e espaço na fase pós-massiva da comunicação contemporânea".

Nesse contexto comunicacional, potencializado pelo suporte tecnológico, existe um maior fluxo de imagens (fotos) e vídeos entre os internautas que possibilita criar a sensação de pertencimento ao grupo e de estar junto em tempo real. Porém, isso é mera ilusão, já que o processo de intersubjetividade torna-se desterritorializado, aberto, presenteísta e esfacelado. De acordo Rivière (2006), o processo de valoração das trocas simbólicas entre os interlocutores circunscreve o presente banal e não as circunstâncias especiais e solenes, porque as fotos são tiradas, observadas e descartadas de maneira imediata, uma vez que basta apenas o aspecto de sociabilidade. Lemos (2007b, p. 32) chama nossa atenção ao fato de que as fotos ou os vídeos não são "produzidos para marcar memória como um arquivo, para ficar no dispositivo, imprimir e guardar em um álbum". E enfatiza que:

O consumo se dá pela circulação na rede, o envio rápido e imediato. Trata-se de circular e não memorizar, para reforçar laços sociais.

[...] o uso e a prática associada a fotos e vídeos por celulares é completamente diferente da prática e uso com câmeras fotográficas e de vídeos tradicionais. $\mathrm{O}$ que importa é tocar o Outro, distante na rede, ou ao meu lado ("veja essa foto que fiz agora"). A ideia não é a exibição na sociedade do espetáculo para o "publico" para a "massa", mas para minha "comunidade individual", pela circulação (LEMOS, 2007b, p. 32). 
Nesse cenário de transição entre o público para a comunidade individual em uma esfera movediça, híbrida tanto em termos comunicacionais (massiva e pós-massiva), quanto ao meio de suporte tecnológico, torna-se essencial traçar um caminho de discussão acerca do processo de alteridade que ultrapasse a dicotomia (estabelecida ao longo dos séculos XIX e XX) entre negros versus brancos, entre homens versus mulheres, enfim, que seja capaz de abarcar e compreender não só os múltiplos agenciamentos que o sujeito sócio histórico está sujeito, mas também atentar-se ao fato de que a identidade é um processo de construção e desconstruções de subjetividades. Cardoso da Silva (2001, p. 45) assevera que:

É preciso conceber a alteridade independente dos essencialismos, como construções produzidas pelas trajetórias dos indivíduos, onde as circunstâncias impõem determinadas respostas, agenciamentos; faz-se necessário, assim, pensar as diferenças enquanto caminhos traçados pelos sujeitos a partir de suas configurações culturais, uma vez que a heterogeneidade não nega 0 entrelaçamento ou a complementaridade.

Pontua-se que é necessário ultrapassar e superar a ênfase em relação aos aspectos de sujeição dos indivíduos ao código cultural, com a finalidade de ressaltar o processo de subjetivação e de individuação deste código pelos atores sociais para significar e ressignificar essa teia de significação ao mesmo tempo. Albuquerque Jr. (1993, p. 88-89) ressalta que:

Como cada indivíduo, ou cada trajetória cultural é uma singularização em relação à configuração cultural de que fazem parte; cada configuração é móvel, ela muda constantemente de acordo com os deslocamentos provocados pelas múltiplas trajetórias culturais que se entrelaçam, se cruzam, se conflitam.

Na medida em que as trajetórias culturais refletem uma sucessão ou coexistências de múltiplos segmentos temporal e espacial, segundo Albuquerque Jr (1993, p. 89), "são diferentes tempos, espaços e vidas que se entrelaçam, cruzam-se na textura dos diversos discursos, práticas e memórias que compõem essas trajetórias". Sendo anuente da relevância do termo cultura no processo de subjetivação e de individuação do sujeito, é essencial tratá-lo como um dispositivo que demarca/delimita a identidade em curso como um constructo dialógico, perfilado por símbolos, por imagens, por discursos que geram uma produção de subjetividade e de individualidade que possibilita compreender o funcionamento da estrutura psíquica do sujeito e observar as implicações desse processo de maneira singular e não de forma homogênea e coletiva. Optar por essa noção de subjetividade significa, para mim como pesquisador, a possibilidade de dialogar e compreender, no século XXI, tanto o processo de singularização do internautaespectador-consumidor, como também as novas maneiras de ressignificar, de participar e colaborar na era da mobilidade informacional. 


\section{Identidade na sobremodernidade}

O fenômeno da mobilidade versus comunicação de massa e o processo de configuração e reconfiguração do território informacional impelem-nos a observar que ter uma identidade fixa é neste mundo fluido, nas palavras de Bauman (2001, p. 11), "uma decisão de certo modo suicida". Tal fenômeno materializa-se pelo fato de que lidar com o mundo metamorfoseado pelas novas mídias digitais impulsiona um processo de introspecção intenso e de constante busca de valoração dos símbolos que nos norteiam dia a dia.

Tais símbolos podem nos incomodar ou não, depende de nossa vulnerabilidade ou estabilidade de tentar desnudá-los com criticidade, racionalidade e equilíbrio, visto que imaginário cultural que circunscreve os símbolos são constituídos por memórias que, de acordo Muxel (1996, p. 230), "atuam no trabalho de reapropriação e negociação que um cada um deve fazer em relação a seu passado para chegar as sua própria individualidade". Por conseguinte, a memória e identidade estão aglutinadas, porque a memória ao mesmo instante que modela 0 ator social é também modelada por eles. Candau (2011, p. 16) pondera que esse processo "resume perfeitamente a dialética da memória e da identidade que se conjugam, nutrem-se mutuamente, apoiam-se uma na outra para produzir uma trajetória de vida, uma história, um mito e uma narrativa".

Evidenciam-se que os símbolos estão estruturados em uma psique descentrada e em pleno processo de intersubjetividade, ancorado em valores culturais, em uma memória social dita "oficial" que nos guiam de forma outorgada. Romper com esse ciclo, demanda do internauta-espectador-consumidor que navega, nas plataformas digitais na era pósdigital, destrinchar as dobras, as teias de significados que são construídos. Em contrapartida, se não ocorrer o desnudamento das teias ou das dobras tornar-se-ão o lócus de segurança e de estabilidade, impossibilitando o confronto e conduzindo a atitude relativista perante os fatos.

É nesse contexto, caro coenunciador, que princípio a discussão acerca do conceito de identidade na sobremodernidade, com propósito de enfatizar tanto o paradigma universal da antropologia: a identidade constrói-se na alteridade, como também outros fatores que estão subjacentes a categoria alteridade. Logo, a alteridade é o primeiro embate de um processo gradual que nos guia durante nossa trajetória em uma sociedade em um intermitente processo de mutação.

Observa-se, no cotidiano, que o processo perceptivo do Outro acerca da diversidade percorre além do mero registro da variedade de aparências, visto que, segundo Sodré (1999, p. 15), "o olhar ao mesmo tempo em que percebe, atribui um valor e, claro, determinada orientação de conduta". Essa conduta está influenciada pela globalização tecnoeconômica, pela comunicação massiva e pós-massiva e pela mobilidade do território informacional, que são consideradas uma etapa qualitativa da planetarização. Esta "aceita a fragmentação territorial", mas por outro lado tem como pressuposto o nivelamento das diferenças de um povo, de uma comunidade e dos seus respectivos costumes, em prol da virtualidade do mercado. Sendo assim, "deixa intocada a questão do etnocentrismo ocidental, a questão essencial da heterogeneidade simbólica" (SODRÉ, 1999, p. 17).

A questão da identidade, nesse contexto, é latente e por isso gera questionamentos acerca de seu processo. Com o intuito de impelir o meu coenunciador a 
compreender de forma pormenorizada a temática identidade, situo o conceito do termo identidade, originado do termo Ipse e Idem. O termo Idem (versão latina do grego auto, "o mesmo"), que é oriundo do latim escolástico em identitas. Em outras palavras, a continuidade/permanência do objeto, uno e idêntico a si mesmo embora sofra as vicissitudes e as pressões de mutação interna e externa. Sodré (1999, p. 35) complementa que o termo Idem latino "faz referência à igualdade ou à estabilidade das representações, possibilidades pela ordem simbólica e pela linguagem, mas também unidade do sujeito consigo mesmo". O termo Ipse, em contrapartida, é o mesmo, no entanto não está relacionado a outro, uma vez que "acolhe na igualdade todas as diferenças", constituindo uma igualdade permeada de particularidades e de singularidades que nos impelem a perceber que não existe "um caminho pronto para se andar, mas o caminho que surge com e ao se andar". (SODRÈ, 1999, p. 37).

Nesse processo, o internauta-espectador-consumidor pode receber, no jogo de espelhos da interface do computador ou dos dispositivos móveis, de seu interlocutor, a própria possibilidade de se identificar. É essencial pontuar que esse processo somente se revela ao homem por intermédio de uma interpelação, em outras palavras, "algo como um juiz, que só fala quando solicitado, neste momento, aparece a diferença entre o ser e o ente. $\mathrm{E}$ todo pertencimento é, assim, uma recíproca escuta na diferença, e toda identificação se dá no comum-pertencer, com acento forte no ato de pertencer" (SODRÉ, 1999, p. 38).

Sodré (1999, p. 39) evidencia que o ser:

[...] deixa de ser um fundamento, um arkhé, enquanto estrutura eternamente estável, para conceber-se como acontecimento (Ereignis), isto é, uma apropriação das propriedades. É só na e pela apropriação que surgem ou podem surgir propriedade. Não há relação de igualdade ou de pura uniformidade entre o ser e o homem, mas de diferença, movimentada historicamente pelo acontecimento.

Ricouer (1985) menciona que a questão da continuidade do tempo está atrelada à ideia de identidade - Idem ou mesmidade. Tal fato pode ser corroborado, quando, no cotidiano, olho para um livro, em seguida, olho para outro, tenho a capacidade de reconhecer o segundo como idêntico ou mesmo que o primeiro. Nesse caso, a identidade é quantitativa, ou seja, o mesmo objeto duas vezes e será, em contrapartida, qualitativa se eu ampliar as similitudes entre eles e explicitar que os dois livros possuem a mesma cor. Na perspectiva de Ricouer (1985), a identidade de si ou Ipseidade é construída em relação com a diferença, ou seja, em um jogo, que funciona por intermédio de aparências distintas, sem lócus para a certeza cartesiana em relação à estabilidade racional/lógica do sujeito de consciência. Sodré $(1999$, p. 46) chama-nos a atenção ao fato de que:

A mesmidade caracteriológica, por outro lado, procede de modo inverso ao da ipseidade: recusa a interpretação histórica e a ficção, pretendendo-se "natural", crendo controlar todos os seus próprios fundamentos. Assim, aparecem as representações racistas, estas são formas interpretativas congelantes da diversidade humana, portanto da dinamicidade histórica do Outro.

Tais representações são produto da cultura, conjunto de mediações simbólicas (língua, costumes, leis, regras, mitos etc.) entre o sujeito e o mundo. De acordo com 
Sodré (1999, p. 46), cabe à cultura responder pela identidade; em outras palavras, "pelas articulações originais que fazem o Um de si mesmo e não outro, tanto pela exclusão como pela inclusão dos outros em potencial e em virtual". E salienta que a ideia de cultura "equivale à de uma "unidade de identificações", capaz de falar - por mitos, por ideologias, por obras de expressão - da igualdade de si mesma, mas sempre na corda bamba de um limite, que é a diferença" (SODRÉ, 1999, p. 46) e elucida que o conceito unidade cultural.

\begin{abstract}
Não se trata de uma unidade de representação (ou seja, um universo fechado de normas, de costumes e de valores) e sim de uma forma, um modo de abordagem do real, onde se entrecruzam discursos e repertórios (valores, significações, padrões de conduta, etc.) portadores de representações de unidade, suportes de processos de estruturação. Em outras palavras, a cultura é um vazio positivo, uma ideia de unidade, mas ideia forte o bastante para levar à invenção tanto de representações de identidade quanto de alteridade. Na prática, o que experimentamos de uma cultura é a variedade de repertórios, onde se embatem simbolizações, hábitos e enunciados. Mas por meio dela, as identidades podem ser reconhecidas (SODRÉ, 1999, p. 47).
\end{abstract}

Sendo assim, pode-se inferir que a cultura assevera a "unidade das identificações" que têm como foco solucionar a diversidade das partes em um cosmo ou em um todo hábil de regular a inserção dos sujeitos/indivíduos na sociedade. Nesse processo, ocorre simultaneamente a noção de cultura, do estético e do político, é essencial pontuar, ao meu leitor, que o político possibilita idealizar as relações sociais que instituem a cidadania, visto que a identidade é auferida por um jogo de agenciamentos e a noção de cultura está atrelada à percepção de regularidade de um objeto (sujeito enquanto produtor de sentido) que concomitantemente torna possível tal objeto.

Por fim, pode-se ponderar que tais questionamentos sobre o processo identitário também são discutidos pela psicanálise contemporânea, que redefine o sujeito como um efeito de linguagem. Por meio dessa premissa, Lacan diferencia a categoria "biológica do indivíduo" da categoria "ego" enquanto instância psíquica, com a finalidade de mostrá-lo como um traço diferencial entre os significantes que se combinam na língua. Por conseguinte, o sujeito é constituído por relações, ancoradas em diferenças, rubricas diversas oriundas dos Outros, com os quais se identifica de forma gradual e, além disso, a identidade, apesar da coesão, é incompleta e para supri-la ocorre, consequentemente, um processo de busca de forma intermitente de outras marcas em prol de uma totalização. Sodré (1999, p. 41) enfatiza que

Não há portanto uma ordem estável e substancial de constituição do sujeito, uma espécie de atribuição colada a um destino metafísico, mas uma dinâmica de interiorização de comportamentos, atitudes e costumes a partir de padrões significativos no ambiente familiar e social. A identificação é fator dinâmico de integração do indivíduo no grupo e de mobilização de suas pulsões, afetos, escolhas. Implica, assim, tanto um ato social como privado, o que faz dela objeto teórico de psicólogos e psicanalistas (GEORGE HERBERT MEAD, SIGMUND FREUD, JACQUES LACAN), sociólogos, antropólogos e filósofos (TALCOTT PARSONS, CLAUDE LÉVI-STRAUSS, JURGEN HABERMAS).

Em todos esses pesquisadores, nota-se a socialização como imperativo dinâmico, 
ou seja, de mediação/permeação do ser particular pela cultura. Deve-se pontuar, neste momento, que as transformações culturais, do século XXI, levam-nos a depreender que a identidade, alicerçada em uma subjetividade homogênea e pela continuidade individual, é, na era da sobremodernidade, substituída por identificações movediças (grupais, afetivas, mediáticas), que engendram novas atitudes do internauta-espectador-consumidor no momento de ressignificar o repertório cultural, social e político nas plataformas digitais.

\section{Considerações finais}

As novas maneiras de apropriação do espaço urbano: o ato de escrever e de ler as múltiplas vozes, materializadas em texto, em imagens, que circulam pelas funções locativas como o mapping, wireless, games, produzem novas dimensões do emprego, da criação de sentidos e de um novo olhar no processo de coconstituição de identidade, em outras palavras, de socialização e de individuação nos espaços urbanos. Esses espaços possibilitam transitar por múltiplos registros: do afeto, da emoção, da paixão, do medo e da alteridade que se consubstanciam por meio de um eixo temporal, uma trajetória coletiva dos internautas-espectadores-consumidores. Dito de outra forma, pela memória dos acontecimentos que delimita uma relação indissociável entre a memória e a identidade, uma vez que se conjugam, nutrem-se mutualmente, apoiam-se no processo de singularização da subjetividade.

Salienta-se que, nesse processo, a percepção ultrapassa o mero registro da variedade das verossimilhanças, visto que o ato de olhar, à medida que percebe, atribui um significado e uma determinada orientação de comportamento. Esse comportamento, potencializado pelas mídias digitais, possibilita aos internautas transformar sua vida prosaica em um grande espetáculo, já que por meio de um clique pode-se materializar, expor-se e compartilhar sensações, conquistas e angústias de maneira incessante, com o intuito de tanto de ressignificar, de participar e de colaborar na era da mobilidade informacional, quanto de vislumbrar sua imagem refletida na tela do computador e de abarcar a sensação de "totalidade", de "unidade", já que tentam mitigar a sensação de fragmentação e de incompletude no processo de desenvolvimento do Eu na supermodernidade com a rubrica do não lugar.

\section{Referências}

ALBUQUERQUE JR, D. M. Vidas por um fio, vidas entrelaçadas rasgando o pano da cultura e descobrindo o rendilhado das trajetórias culturais. História \& Perspectivas, Uberlândia, n. 8, p. 87-95, jan./jun. 1993.

BAUMAN, Z. Modernidade líquida. Rio de Janeiro: ZAHAR, 2001.

CANDAU, J. Memória e identidade. São Paulo: Contexto, 2011.

CARDOSO DA SILVA, F. C. (Des) Construção de identidade Étnica-racial em Salvador: o MNU e o llê Aiyê no combate ao racismo. Dissertação do Mestrado em Sociologia - 
UFPB, Campina Grande, 2001.

DELEUZE, G.; GUATARRI, F. Mille Plateaux. Capitalisme et Schizophrénie. Paris Les Editions de Minuit, 1980.

HARVEY, D. Condição pós-moderna: uma pesquisa sobre as origens da mudança cultural. 6 ed, São Paulo: Loyola, 1992.

LEMOS, A. Cidades e Mobilidade, Telefones Celulares, funções pós-massivas e territórios informacionais. Matrizes, Revista do Programa de Pós-Graduação em Ciências da Comunicação, São Paulo, ano 1, n. 1, p. 121-137, 2007a.

LEMOS, A. Comunicação e práticas sociais no espaço urbano: as características dos dispositivos híbridos móveis de conexão multirredes (DHMCM). Revista Comunicação, Mídia e Consumo, São Paulo, v. 4, n. 10, p. 23-40, jul. 2007b.

LEMOS, A. Mídia locativa e território informacional. In.: ARANTES, P; SANTAELLA, L (org.). Estéticas Tecnológicas. Novos modos de sentir. Ed. EDUC/SP, 2008, p. 9-30.

LEMOS, A. Nova esfera conversacional. In.: DIMA, A.; KUNSCH, D. A.; DA SILVEIRA, S. A. et al. Esfera pública, redes e jornalismo. Rio de Janeiro, Ed. E-Papers, 2009, p. p. 207230.

MUXEL, A. Individue et memoire familiale. Paris: Nathan, 1996.

TUAN, Yi-Fu. Space and Place. The perspective of Experience. University of Minnesota Press, Minneapolis/London, 2003.

RIVIERE, C. A. Teléphone mobile et photographie: les forms des sociabilités visuelles au quotidian. Societés, Bruxelas: De Boeck, n. 91, p. 119-134, 2006.

RICOEUR, P. Soi-même comme un Autre. Seuil, 1985.

SODRÉ, M. Claros e escuros: identidade, povo e mídia no Brasil. Petrópolis, RJ: Vozes, 1999. 